\title{
Complications of gastrectomy with lymphadenectomy in gastric cancer
}

\author{
Bruno Zilberstein, Bruno da Costa Martins, Carlos Eduardo Jacob, Cláudio Bresciani, \\ Fábio Pinatel lopasso, Roberto de Cleva, Paulo Engler Pinto Junior, Ulysses Ribeiro Junior, \\ Rodrigo Oliva Perez, and Joaquim Gama-Rodrigues \\ Department of Gastroenterology, University of São Paulo School of Medicine, Av 9 de Julho 4440, São Paulo, SP 01406-100, Brazil
}

\begin{abstract}
Background. Currently, gastrectomy and extended lymphadenectomy (LN) is the treatment of choice for gastric cancer. Although a survival rate benefit of D2 LN compared to D1 LN has been shown, the D2 LN procedure is not fully employed, due to possible higher morbidity and mortality rates. These higher rates are being questioned in more recent series, in which D1 and D2 LN complication rates have been similar. The aim of this study was to analyze the immediate postoperative complications of patients submitted to total or subtotal gastrectomy with D1 or D2 LN (according to the Japanese guidelines for gastric cancer) at the Gastrointestinal Surgery Division of the Medical School of São Paulo University, between January 2001 and April 2003.

Methods. One hundred consecutive patients were studied; 61 were men and 39, women. Total gastrectomy was performed in 52 patients (13 with D1 LN and 39 with D2 LN), and subtotal gastrectomy was performed in 48 (11 with D1 LN and 37 with D2 LN). Total or subtotal gastrectomy with D1 or D2 LN was performed according to the tumor extent and histological classification (Lauren's diffuse or intestinal type), considering the patient's general condition and the gastric cancer stage. Roux-en-Y reconstruction was performed in almost all patients.

Results. No difference was observed regarding complications and mortality related to the extent of the gastrectomy. Although morbidity was higher in the D1 group, no significant difference was observed. Mortality was higher in the D1 group, and this was probably related to their poor surgical condition and more advanced tumors.

Conclusion. According to these results, it appears that total or subtotal gastrectomy with D2 LN in gastric cancer treatment, performed according to the Japanese guidelines, can be considered a safe procedure, with acceptable morbidity and mortality, when performed by a trained surgical team.
\end{abstract}

Key words Gastric cancer · Lymphadenectomy · Gastrectomy · Complications

Offprint requests to: $\mathrm{B}$. Zilberstein

Received: January 19, 2004 / Accepted: August 20, 2004

\section{Introduction}

Gastric cancer remains one of the most common tumors worldwide, with significant mortality rates [1].

Radical resection with free-margin gastrectomy and extended lymphadenectomy (LN) is the preferred surgical strategy in Asian centers. The extension of the lymph node resection is associated with better survival rates, and D2 LN seems to be superior to D1 [2-5]. However, D2 resection can be associated with higher morbidity and/or mortality rates [6,7]. These results, attributed to the extended lymph node resection, could be related to the surgical team's experience, as well as their learning curve and knowledge in regard to complications of treatment. It is possible, therefore, that D1 and D2 may have similar morbidity and mortality rates, and this would enhance the beneficial effects of D2 [8-10].

The aim of this study was to analyze the impact on morbidity and mortality of D2 LN when compared with D1 LN in patients with GC submitted to total or subtotal gastrectomy at our Institution during the past 3 years.

\section{Patients and methods}

Between 2001 and 2003, 100 consecutive patients submitted to gastrectomy for gastric adenocarcinoma were studied. There were 61 men and 39 women. The median age was $61.5 \pm 13.1$ years, ranging from 33 to 87 years. Twenty-nine patients (29\%) had an early gastric cancer, confirmed by postoperative histological examination, and 71 patients $(71 \%)$ had an advanced cancer.

The indication for performing either total or subtotal gastrectomy was based on tumor location and surgical tumor-free margins. Proximal surgical margins were determined according to the Japanese Gastric Cancer 
Table 1. Patient distribution according to extent of lymphadenectomy

\begin{tabular}{|c|c|c|c|}
\hline Parameters & $\mathrm{D} 1(n=24)$ & $\mathrm{D} 2(n=76)$ & $P$ value \\
\hline \multicolumn{4}{|l|}{ Sex } \\
\hline Male & 16 & 45 & \multirow[t]{2}{*}{$0.3^{\mathrm{a}}$} \\
\hline Female & 8 & 31 & \\
\hline Mean age; years (SD) & $61.8( \pm 22)$ & $61.5( \pm 12.3)$ & $0.9852^{\mathrm{b}}$ \\
\hline \multicolumn{4}{|l|}{ Type of operation } \\
\hline STG & 11 & 37 & \multirow[t]{2}{*}{$0.8074^{\mathrm{a}}$} \\
\hline $\mathrm{TG}$ & 13 & 39 & \\
\hline \multicolumn{4}{|l|}{ Type of reconstruction } \\
\hline Roux-en-Y & 23 & 74 & \\
\hline B II & 1 & 2 & \\
\hline Resection of other organs & 3 & 13 & $0.23^{\mathrm{a}}$ \\
\hline Mean surgical time; min (SD) & $381( \pm 116)$ & $412( \pm 86)$ & $0.25^{\mathrm{b}}$ \\
\hline $\begin{array}{l}\text { Mean anesthetic time; } \\
\text { min (SD) }\end{array}$ & $464( \pm 127)$ & $493( \pm 87)$ & $0.26^{\mathrm{b}}$ \\
\hline Patients with transfusion & 18 & 43 & $0.10^{\mathrm{a}}$ \\
\hline Complications & 24 & 76 & $0.22^{\mathrm{a}}$ \\
\hline $\begin{array}{l}\text { Number of patients with } \\
\text { complications }\end{array}$ & $11(45.8 \%)$ & $21(27.6 \%)$ & $0.09^{\mathrm{a}}$ \\
\hline $\begin{array}{l}\text { Mean number of dissected } \\
\text { lymph nodes (SD) }\end{array}$ & $29( \pm 15.5)$ & $46( \pm 18.7)$ & $0.004^{\mathrm{b} *}$ \\
\hline \multicolumn{4}{|l|}{$\mathrm{T}$} \\
\hline $\mathrm{T} 1$ & 3 & 26 & \multirow[t]{4}{*}{$0.0183^{\mathrm{a}}$} \\
\hline $\mathrm{T} 2$ & 3 & 14 & \\
\hline T3 & 14 & 34 & \\
\hline $\mathrm{T} 4$ & 4 & 2 & \\
\hline \multicolumn{4}{|l|}{$\mathrm{N}$} \\
\hline N1 & 8 & 23 & \multirow[t]{3}{*}{$0.25^{\mathrm{a}}$} \\
\hline N2 & 4 & 13 & \\
\hline N3 & 5 & 3 & \\
\hline \multicolumn{4}{|l|}{ M } \\
\hline M0 & 21 & 74 & \multirow[t]{2}{*}{$0.0531^{\mathrm{a}}$} \\
\hline M1 & 3 & 2 & \\
\hline \multicolumn{4}{|l|}{ Stage } \\
\hline Ia & 1 & 24 & \multirow[t]{6}{*}{$0.0686^{\mathrm{a}}$} \\
\hline $\mathrm{Ib}$ & 2 & 9 & \\
\hline II & 5 & 13 & \\
\hline IIIa & 5 & 11 & \\
\hline IIIb & 5 & 14 & \\
\hline IV & 5 & 5 & \\
\hline
\end{tabular}

TG, Total gastrectomy; STG, subtotal gastrectomy

* Statistically significant

${ }^{\mathrm{a}} \chi^{2}$ test

${ }^{\mathrm{b}}$ Student's $t$-test

Association (JGCA) recommendations considering the histological type (Nakamura's differentiated or undefferentiated and/or Lauren's intestinal or diffuse type). For differentiated/intestinal-type tumors, a surgical margin of at least $5 \mathrm{~cm}$ was observed, and the surgical margin was at least $10 \mathrm{~cm}$ for undefferentiated/ diffuse-type tumors. Subtotal gastrectomy was performed in 48 patients (D1 LN in 11, and D2 LN in 37). Total gastrectomy was performed in 52 patients (D1 LN in 13, and D2 LN in 39; Table 1).

D2 lymphadenectomy was performed according to the Japanese Research Society for the Study of Gastric Cancer (JRSGC) guidelines. D1 lymphadenectomy was performed only in patients with severe comorbidities or in patients with early gastric cancer with minimal tu- mors and low probability of lymph node metastasis according to the Japanese criteria. There were 76 D2 LN resections and $24 \mathrm{D} 1 \mathrm{LN}$ resections. The mean number of dissected lymph nodes was $29 \pm 15.5$ in D1 LN and $46 \pm 18.7$ in D2 LN (Table 1).

Roux-en-Y reconstruction was employed in 97 patients, and Billroth II (B II) in 3.

Postoperative complications were studied, considering the extent of the gastric resection and extent of the LN; with analysis of mean surgical and anesthetic times, necessity for transfusion, associated resected organs, mean number of dissected and metastatic lymph nodes, and tumor stage (TNM). The statistical analysis was performed utilizing the $\chi^{2}$ test and Student's $t$-test, with $95 \%$ confidence intervals. 
Table 2. Patient distribution according to occurrence of complications

\begin{tabular}{|c|c|c|c|}
\hline Parameters & Complications $(n=33)$ & No complications $(n=67)$ & $P$ value \\
\hline Mean age; years (SD) & $65.3( \pm 12.4)$ & $59.7( \pm 13.2)$ & $0.03^{\mathrm{b}}$ \\
\hline \multicolumn{4}{|l|}{ Type of operation } \\
\hline STG & 12 & 35 & \multirow[t]{2}{*}{$0.1347^{\mathrm{a}}$} \\
\hline TG & 21 & 32 & \\
\hline \multicolumn{4}{|l|}{ Type of lymphadenectomy } \\
\hline D1 & 10 & 14 & \multirow[t]{2}{*}{$0.22^{\mathrm{a}}$} \\
\hline D2 & 23 & 53 & \\
\hline \multicolumn{4}{|l|}{ Type of reconstruction } \\
\hline Roux-en-Y & 32 & 65 & \multirow[t]{2}{*}{$0.8604^{\mathrm{a}}$} \\
\hline B II & 1 & 2 & \\
\hline Resection of other organs & 9 & 7 & $0.0309^{\mathrm{a} *}$ \\
\hline $\begin{array}{l}\text { Mean surgical time; } \\
\text { min (SD) }\end{array}$ & $409( \pm 86)$ & $402( \pm 95)$ & $0.9396^{\mathrm{b}}$ \\
\hline $\begin{array}{l}\text { Mean anesthetic time; } \\
\text { min (SD) }\end{array}$ & $486( \pm 87)$ & $486( \pm 95)$ & $1.0000^{\mathrm{b}}$ \\
\hline Patients with transfusion & 22 & 39 & $0.26^{\mathrm{a}}$ \\
\hline $\begin{array}{l}\text { Mean number of dissected } \\
\text { lymph nodes (SD) }\end{array}$ & $45.2( \pm 27)$ & $41.1( \pm 16)$ & $0.28^{\mathrm{a}}$ \\
\hline $\begin{array}{l}\text { Mean number of metastatic } \\
\text { lymph nodes (SD) }\end{array}$ & $5.6( \pm 13.2)$ & $5.7( \pm 11)$ & $0.9932^{\mathrm{b}}$ \\
\hline \multicolumn{4}{|l|}{$\mathrm{T}$} \\
\hline $\mathrm{T} 1$ & 9 & 20 & \multirow[t]{4}{*}{$0.8153^{\mathrm{a}}$} \\
\hline $\mathrm{T} 2$ & 6 & 11 & \\
\hline T3 & 15 & 33 & \\
\hline $\mathrm{T} 4$ & 3 & 3 & \\
\hline Early & 9 & 20 & \multirow[t]{2}{*}{$0.7893^{\mathrm{a}}$} \\
\hline Advanced & 24 & 47 & \\
\hline \multicolumn{4}{|l|}{$\mathrm{N}$} \\
\hline N1 & 10 & 21 & \multirow[t]{3}{*}{$0.9731^{\mathrm{a}}$} \\
\hline $\mathrm{N} 2$ & 6 & 11 & \\
\hline N3 & 2 & 6 & \\
\hline $\mathrm{N}+$ & 18 & 38 & \multirow[t]{2}{*}{$0.8371^{\mathrm{a}}$} \\
\hline N0 & 15 & 29 & \\
\hline \multicolumn{4}{|l|}{ M } \\
\hline M0 & 32 & 63 & \multirow[t]{2}{*}{$0.5259^{\mathrm{a}}$} \\
\hline M1 & 1 & 4 & \\
\hline \multicolumn{4}{|l|}{ Stage } \\
\hline Ia & 7 & 19 & \multirow[t]{6}{*}{$0.7912^{\mathrm{a}}$} \\
\hline $\mathrm{Ib}$ & 5 & 6 & \\
\hline II & 7 & 11 & \\
\hline IIIa & 5 & 11 & \\
\hline IIIb & 7 & 12 & \\
\hline IV & 2 & & \\
\hline
\end{tabular}

TG, Total gastrectomy; STG, subtotal gastrectomy

* Statistically significant

${ }^{\mathrm{a}} \chi^{2}$ test

${ }^{\mathrm{b}}$ Student's $t$-test

\section{Results}

The results are presented in Table 1 (patient distribution according to the extent of $\mathrm{LN}$ ), Table 2 (patient distribution according to occurrence of complications), and Table 3 (postoperative complications and mortality rates according to extent of the $\mathrm{LN}$ ).

Of the 24 patients with D1 LN, 5 developed respiratory complications $(20.8 \%)$, which were treated with antibiotics and ventilatory support, with full recovery in
3 of them and two deaths. Three patients developed anastomotic leakage. One of these patients had a duodenal stump fistula, which was treated by conservative management. One of the other two patients developed an esophagojejunal fistula, and the other patient had a gastrojejunal fistula; both died of abdominal sepsis. The overall morbidity rate was $45.8 \%$. Fatal outcomes were observed in 5 patients $(20.8 \%)$ (Table 3).

Of the 76 patients with D2 LN, 5 developed respiratory complications $(6.5 \%)$, which were treated by anti- 
Table 3. Postoperative complications and mortality rates according to extent of lymphadenectomy

\begin{tabular}{|c|c|c|c|c|}
\hline & $\mathrm{D} 1(n=24)$ & $\mathrm{D} 2(n=76)$ & $\chi^{2}$ value & Total $(n=100)$ \\
\hline Leakage & $3(12.5 \%)$ & $5(6.5 \%)$ & 0.3513 & $8(8 \%)$ \\
\hline Cavitary abscess & 0 & $7(9.2 \%)$ & 0.1231 & $7(7 \%)$ \\
\hline Respiratory complications & $5(20.8 \%)$ & $5(6.5 \%)$ & $0.0424 *$ & $10(10 \%)$ \\
\hline Acute renal failure & 0 & $4(5.2 \%)$ & 0.2513 & $4(4 \%)$ \\
\hline Total no. of patients & $11(45.8 \%)$ & $21(27.6 \%)$ & 0.0956 & $32(32 \%)$ \\
\hline Mortality & $5(20.8 \%)$ & $3(3.9 \%)$ & $0.0078 *$ & $8(8 \%)$ \\
\hline
\end{tabular}

* Statistically significant

biotics and ventilatory support, with full recovery in 4 , and one death, which was associated with abdominal sepsis due to jejunostomy leakage. Five patients $(6.5 \%)$ developed anastomotic leakage (4 due to duodenal stump fistula and 1 due to esophagojejunal fistula), which was managed conservatively in 4 patients and surgically in 1 patient (duodenal stump fistula). Seven patients $(9.2 \%)$ developed cavitary abscesses, mostly in the left subphrenic space. Four were treated conservatively with drainage and antibiotics, and 3 were operated, with one death. The overall morbidity rate was $27.6 \%$. Fatal outcomes were observed in 3 patients $(3.9 \%)$ (Table 3$)$.

The incidence of complications was higher in the D1 LN group, but this difference was not statistically significant $(P=0.09)$. When complications were considered individually, respiratory complications were the only ones that reached a statistically significant difference between the D1 LN and D2 LN groups $(P=0.04)$. Although seven patients in the D2 LN group had cavitary abscesses and in the D1 LN group none, had this complication, the difference was not statistically significant $(P=0.12)$.

Also, associated resection of other organs showed an important correlation with morbidity, independently of the extent of the LN or the gastrectomy (Table 2).

Mortality rates were significantly higher in patients treated by D1 LN (20.8\%) when compared to D2 LN $(3.9 \%)$.

\section{Discussion}

Extended LN was introduced in Japan in late 1960, for the treatment of gastric cancer, and has been shown to be associated with better overall survival [11,12]. Since that time, this procedure has been well accepted in Japan and is currently the procedure of choice for the treatment of gastric cancer in Japan.

In the Western world, an early review of 1983 patients with gastric cancer treated by extended lymphadenectomy, reported by Gilbertsen [13], showed no beneficial effect on overall survival rates. These results led several centers in the West to abandon this procedure as the preferred treatment strategy.

Advances in intensive care, anesthesiology, and perioperative procedures have significantly reduced the morbidity and mortality rates associated with major gastric operations $[5,14,15]$. Furthermore, the excellent results obtained in Japan with extended LN for the treatment of gastric cancer [16] have led to several studies that have compared survival, and morbidity and mortality rates associated with different LN procedures.

In the Netherlands, a randomized multicenter study was performed between 1990 and 1993, including 33 hospitals and 70 surgeons [6]. Higher morbidity and mortality rates were observed in the group of patients treated by D2 LN. However, in this study, there was significant heterogeneity in surgical techniques leading to inadequate lymph node dissection, i.e., the resection of lymph nodes that were not supposed to be removed, or the missing of those that were supposed to be removed [11]. Similar results were observed in the United Kingdom in prospective and randomized trials [7].

In both the above studies [6,7], the higher mortality and morbidity rates in patients treated by D2 LN were closely related to postoperative complications associated with splenectomy and distal pancreatectomy $[7,10,17]$.

In Germany, 1654 patients treated for gastric cancer were studied between 1986 and 1989. Patients treated by D2 LN had at least 25 lymph nodes removed, and those in stages II and IIIa showed better overall survival than patients treated by D1 LN. Morbidity and mortality rates were similar in both groups, independent of the LN extent [4]. In the United States, similar results were observed. Furthermore, mortality rates associated with D2 LN were as low as $1.6 \%$ [10].

Several studies have shown that other factors can be related to an unpleasant outcome after gastrectomy for gastric cancer, and that they be even more important that the LN extent; for example, splenectomy or associated organ resection [10,18-20], as shown in this study. 
Table 4. Differences in morbidity and mortality rates in patients submitted to gastric resection for gastric cancer at several centers worldwide

\begin{tabular}{|c|c|c|c|c|}
\hline & \multicolumn{2}{|c|}{ Morbidity } & \multicolumn{2}{|c|}{ Mortality } \\
\hline & D1 & D2 & D1 & $\mathrm{D} 2$ \\
\hline Bonenkamp et al. [6] 1995 & $25 \%$ & $43 \%$ & $4 \%$ & $10 \%$ \\
\hline Cuschieri et al. [7] 1996 & $28 \%$ & $46 \%$ & $6.5 \%$ & $13 \%$ \\
\hline Siewert et al. [4] 1993 & $28.9 \%$ & $30.5 \%$ & $5.1 \%$ & $5 \%$ \\
\hline Smith et al. [5] 1991 & $35 \%$ & $44 \%$ & 0 & $1.6 \%$ \\
\hline Jentschura et al. [8] 1997 & - & $25.7 \%$ & - & $7.5 \%$ \\
\hline Roviello et al. [9] 2002 & - & $17 \%$ & - & $2 \%$ \\
\hline NCC - Tokyo [2] 1993 & - & - & $0.5 \%$ & $1 \%$ \\
\hline This study & $45.8 \%$ & $27.6 \%$ & $20.8 \%$ & $3.9 \%$ \\
\hline
\end{tabular}

The higher morbidity and mortality rates observed in our patients treated by D1 LN could be explained by their poor medical condition, which determined the choice of a limited surgical procedure. It must also be considered that, in this group, there were only three patients with early gastric cancer; therefore, most patients in this group had advanced disease, thus enhancing the poor results.

D2 LN was performed in most of the patients, reflecting our standard procedure following the Japanese guidelines. The good postoperative outcome was probably related to a good selection of patients, and also to a standardized pattern of lymph node dissection. For differences in the morbidity and mortality rates of patients submitted to gastric resection for gastric cancer in several centers worldwide, see Table 4.

\section{Conclusion}

In conclusion, the extended LN dissection (D2) in this study was not associated with higher morbidity and mortality rates than the D1 procedure. Therefore, the D2 procedure can be strongly considered in the surgical strategy for curative gastric cancer management.

It is noteworthy that the mortality and morbidity rates after D2 LN were lower than those reported in the Western literature [6,7]. This could be explained by our extensive experience with the Japanese lymph node dissection method, achieved at our institution in the past 30 years.

\section{References}

1. Jacob CE. Câncer gástrico - estudo da evolução topográfica, sexo e idade em pacientes submetidos a tratamento cirúrgico no decorrer de 28 anos. Dissertação de mestrado, Departamento de Gastroenterologia FMUSP, 1999.
2. Maruyama K, Sasako M, Kinoshita T, Okajima K. Effectiveness of systematic lymph node dissection in gastric cancer surgery. In: Nishi M, Ichikawa H, Nakajima T, Maruyama K, Tahara E, editors. Gastric cancer. Berlin Heidelberg New York Tokyo: Springer; 1993.

3. Shiu MH, Moore E, Sanders M, Huvos A, Freedman B, Goodbold J, et al. Influence of the extent of resection on survival after curative treatment of gastric carcinoma: a retrospective multivariate analysis. Arch Surg 1987;122:1347-52.

4. Siewert JR, Boettcher K, Roder JD, Busch R, Hermanek P, Meyer HJ. German Gastric Carcinoma Study Group. Prognostic relevance of systematic lymph node dissection in gastric carcinoma. Br J Surg 1993;80:1015-8.

5. Smith JW, Shiu MH, Kelsey L, Brennan MF. Morbidity of radical lymphadenectomy in the curative resection of gastric carcinoma. Arch Surg 1991;126:1469-73.

6. Bonenkamp JJ, Songun I, Hermans J, Sasako M, Welvaart K, Plukker JT, et al. Randomised comparison of morbidity after D1 and D2 dissection for gastric cancer in 996 Dutch patients. Lancet 1995;345:745-8.

7. Cuschieri A, Fayers P, Fielding J, Craven J, Bancewicz J, Joypaul V, Cook P. Postoperative morbidity and mortality after D1 and D2 resections for gastric cancer: preliminary results of the MRC randomised controlled surgical trial. Lancet 1996;347:9959.

8. Jentschura D, Heubner C, Manegold B, Trede M. Surgery for early gastric cancer: a European one-center experience. World J Surg 1997;21:845-9.

9. Roviello F, Marrelli D, Morgagni P, Kurihara H. Survival benefit of extended D2 lynphadenectomy in gastric cancer with involvement of second level lymph nodes: a longitudinal multicenter study. Ann Surg Oncol 2002;9:894-900.

10. Siewert JR, Boettcher K, Stein HJ, Roder JD. Relevant prognostic factors in gastric cancer: 10 years results of the German Gastric Cancer Study. Ann Surg 1998;228:449-61.

11. Gama-Rodrigues J, Zilberstein B, Jacob CE, Bresciani C, Jureidini R, Iriya K, et al. Papel da linfadenectomia no tratamento cirúrgico radical do câncer gástrico: fundamentos, resultados e análise crítica. Em Atualização em Cirurgia do Aparelho Digestivo e em Coloproctologia - Gastrão 2000.

12. Jinnai D. Evaluation of extended radical operation for gastric cancer with regard to lymph node metastasis and follow-up results. Gann Monogr Cancer Res 1968;3:225-31.

13. Gilbertsen VA. Results of treatment of stomach cancer. An appraisal of efforts for more extensive surgery and a report of 1983 cases. Cancer 1969;23:1305-8.

14. Irvin T, Bridger J. Gastric Cancer: an audit of 122 consecutive cases of the results of the R1 gastrectomy. Br J Surg 1988;1069. 
15. Macintyre IMC, Akoh JA. Improving survival in gastric cancer: review of operative mortality in English language publications from 1970. Br J Surg 1991;78:771-3.

16. Maruyama K, Okabayashi K, Kinoshita T. Progress in gastric cancer surgery in Japan and its limits of radicality. World J Surg 1987;11:418-25.

17. Sasako M, for the Dutch Gastric Cancer Study Group. Risk factors for surgical treatment in the Dutch Gastric Cancer Trial. Br J Surg 1997;84:1567-71.
18. Adachi Y, Mimori K, Mori M, Maehara Y, Sugimachi K. Morbidity after D2 and D3 gastrectomy for node-positive gastric carcinoma. J Am Coll Surg 1997;184(3):240-4.

19. Ikeguchi M, Oka S, Gomyo Y, Tsujitani S, Maeta M, Kaibara N. Postoperative morbidity and mortality after gastrectomy for gastric carcinoma. Hepatogastroenterology 2001;48(41):1517-20.

20. Roder JD, Bottcher K, Siewert JR, Busch R, Hermanek P, Meyer HJ and the German Gastric Cancer Study Group. Prognostic factors in gastric carcinoma. Cancer 1993;72:2089-97. 